\title{
Prevalence of microalbuminuria in type 2 diabetes mellitus at a diabetes centre in southern India
}

\author{
A Varghese, R Deepa, M Rema, V Mohan
}

\begin{abstract}
Objective-The aim of this study was to determine the prevalence and risk factors for microalbuminuria among south Indian type 2 diabetic patients attending a diabetes centre.

Methods-One thousand four hundred and twenty five type 2 diabetic patients attending a diabetes centre in south India were recruited for the study. Urinary albumin concentration was measured by immunoturbodimetric assay. Microalbuminuria was diagnosed if the urinary albumin excretion was $>30 \mathrm{mg} / \mathrm{g}$ of creatinine.

Results-Overall prevalence of microalbuminuria was $36.3 \%$ ( $95 \%$ confidence interval 33.8 to 38.9 ). The prevalence of microalbuminuria increased with the increase in duration of diabetes. Multivariate regression analysis revealed age, diastolic blood pressure, glycated haemoglobin, fasting plasma glucose, and duration of diabetes to be associated with microalbuminuria.

Conclusion-The overall prevalence of microalbuminuria in this south Indian clinic population and its risk factors are similar to that reported in Europeans. (Postgrad Med F 2001;77:399-402)
\end{abstract}

Keywords: microalbuminuria; diabetes; type 2 diabetes; south India

Diabetic nephropathy is the leading cause of end stage renal disease world wide. ${ }^{12}$ Microalbuminuria is considered to be an early stage of diabetic nephropathy. ${ }^{3-6}$ Microalbuminuria is also considered to be a predictor for cardiovascular disease both among diabetic and nondiabetic subjects, ${ }^{7-9}$ and is one of the components of the metabolic syndrome (insulin resistance syndrome). ${ }^{10}{ }^{11}$ Recent statistics from the World Health Organisation (WHO) project an increase in the prevalence of diabetes world wide particularly in developing countries. ${ }^{12}$ Currently, India leads the world with the largest number of diabetic subjects and this is expected to further rise in the coming years. ${ }^{12}{ }^{13}$ Hence studies on diabetes related complications are essential to assess the burden of diabetes. In this study we report on the prevalence of microalbuminuria in south Indian type 2 diabetic patients attending a diabetes centre in southern India.

\section{Patients and methods}

The study group comprised of 1620 consecutive type 2 diabetic patients attending the $\mathrm{M} \mathrm{V}$ Diabetes Specialities Centre, a large diabetes centre at Chennai in southern India, during the period from 1 January 1998 to 31 March 1998. Type 2 diabetes was diagnosed based on the WHO study group report criteria. ${ }^{14}$ Patients with incomplete records, presence of urinary tract infection, or heart failure were excluded $(\mathrm{n}=90)$. Of the remaining 1530 patients, 105 $(6.9 \%)$ subjects had proteinuria $\geqslant 500 \mathrm{mg} /$ day, and these patients were also excluded from the study as we have separately reported on the prevalence of proteinuria. ${ }^{15}$ Thus a total of 1425 individuals were included in the study.

In all study patients, a complete clinical work up was done including height, weight, and body mass index. The body mass index was calculated and expressed as $\mathrm{kg} / \mathrm{m}^{2}$. The blood pressure was recorded in the right upper arm in the sitting posture, after a five minute rest. Patients were categorised as being hypertensive if they were on antihypertensive treatment or if they had a systolic blood pressure $>140 \mathrm{~mm}$ $\mathrm{Hg}$ and/or diastolic blood pressure $>90 \mathrm{~mm}$ Hg. ${ }^{16} \mathrm{~A}$ fasting sample of blood was drawn after an overnight fast of 10 hours and the following investigations were done: plasma glucose, serum cholesterol, serum triglycerides, high density lipoprotein-cholesterol, and serum creatinine.

Biochemical analysis were done on Ciba Corning Express Plus Auto Analyser (Corning, Medfield, MA, USA) using kits supplied by Boehringer Mannheim, (Mannheim, Germany). Fasting and postprandial plasma glucose (glucose oxidase method), serum cholesterol (CHOD-PAP method), serum triglycerides (GPO-PAP method), and serum creatinine (modified kinetic method of Jaffe) were estimated in all patients. Glycated haemoglobin ( $\mathrm{HbA} 1 \mathrm{c})$ was estimated by high pressure liquid chromatography using the Variant machine (Bio Rad, Hercules, CA, USA).

Urine samples were collected in the early morning after an overnight fast. Urine creatinine was measured using Jaffe's method. Urine microalbumin concentration was measured using commercially available immunoturbidometric assay kits from Randox ( Randox, UK) on Opera Technicon Auto Analyser (Bayer Diagnostics, USA). The urine sample was added to a buffer containing antibody specific for human serum albumin. The absorbance of the resulting turbid solution is proportional to the concentration of albumin in the sample solution. By constructing a standard curve from the absorbances of the standards, the albumin concentration in the sample can be determined. The mean interassay and intraassay coefficient of variation were $3.4 \%$ and $2.4 \%$ respectively.
Submitted 16 May 2000 Accepted 2 October 2000 
Table 1 Clinical and biochemical characteristics of the study subjects

\begin{tabular}{|c|c|c|c|}
\hline Parameters & $\begin{array}{l}\text { Normoalbuminuric } \\
\text { group }(n=907)\end{array}$ & $\begin{array}{l}\text { Microalbuminuric } \\
\text { group }(n=518)\end{array}$ & $p$ Value \\
\hline Age (years) & $51(10)$ & $54(11)$ & $<0.001$ \\
\hline Male (\%) & $577(63.6 \%)$ & $299(57.7 \%)$ & 0.03 \\
\hline Age at diagnosis (years) & $45(10)$ & $46(11)$ & NS \\
\hline Duration of diabetes (years) & $6(6)$ & $8(7)$ & $<0.001$ \\
\hline Body mass index $\left(\mathrm{kg} / \mathrm{m}^{2}\right)$ & $25.2(4.2)$ & $24.8(4.1)$ & NS \\
\hline Systolic BP (mm Hg) & $133(16)$ & $138(17)$ & $<0.001$ \\
\hline Diastolic BP (mm Hg) & $83(7)$ & $84(8)$ & 0.013 \\
\hline Fasting blood glucose $(\mathrm{mmol} / \mathrm{l})$ & $9.9(3.6)$ & $11.5(4.8)$ & $<0.001$ \\
\hline HbAlc $(\%)$ & $9.1(2.2)$ & $9.7(2.3)$ & $<0.001$ \\
\hline Serum creatinine $(\mu \mathrm{mol} / \mathrm{l})$ & $80.4(29.2)$ & $84.1(19.4)$ & 0.010 \\
\hline Serum cholesterol $(\mathrm{mmol} / \mathrm{l})$ & $5.0(1.0)$ & $5.0(1.1)$ & NS \\
\hline Serum triglycerides $(\mathrm{mmol} / \mathrm{l})$ & $2.2(1.6)$ & $2.2(2.0)$ & NS \\
\hline $\begin{array}{l}\text { High density lipoprotein-cholesterol } \\
(\mathrm{mmol} / \mathrm{l})\end{array}$ & $1.0(0.26)$ & $1.0(0.34)$ & NS \\
\hline \multicolumn{4}{|l|}{ No (\%) with ischaemic heart disease } \\
\hline Ischaemia & $45(5)$ & $47(9)$ & 0.002 \\
\hline Infarction & $18(2)$ & $15(3)$ & NS \\
\hline \multicolumn{4}{|l|}{ No (\%) with retinopathy } \\
\hline NPDR & $72(8)$ & $83(16)$ & $<0.001$ \\
\hline NPDR with maculopathy & $45(5)$ & $62(12)$ & $<0.001$ \\
\hline Proliferative retinopathy & $7(0.8)$ & $14(3)$ & $<0.001$ \\
\hline Peripheral vascular disease & $6(0.7)$ & $7(3.3)$ & $<0.001$ \\
\hline Neuropathy & $45(5.0)$ & $64(12.4)$ & $<0.001$ \\
\hline
\end{tabular}

Data are $\mathrm{No}(\%)$ or mean $(\mathrm{SD}) . \mathrm{NPDR}=$ non-proliferative diabetic retinopathy; $\mathrm{BP}=$ blood pressure; HbA1c = glycated haemoglobin.

\section{DEFINITIONS}

Microalbuminuria was diagnosed if the albumin creatinine ratio exceeded $30 \mathrm{mg} / \mathrm{g}$ of creatinine.

The ocular fundi were examined by a retinal specialist both by direct and indirect ophthalmoscopy, after complete mydriasis. Retinopathy when present was classified as nonproliferative diabetic retinopathy (NPDR) and proliferative diabetic retinopathy (PDR). NPDR was diagnosed when there was evidence of microaneurysms, dot haemorrhages, exudates, or cotton wool spots in the absence of any new vessels or advanced diabetic eye disease. PDR was diagnosed when any new vessels were present or if there was evidence of fibrous retinitis proliferans, vitreous haemorrhage, retinal detachment, or other features of advanced diabetic eye disease.

Ischaemic heart disease was considered to be present when either myocardial ischaemia or infarction was present.

Myocardial ischaemia was diagnosed if there was a history of exertional chest pain (angina) with unequivocal $\mathrm{T}$ wave changes in the electrocardiogram (ECG), but no evidence of infarction.

Myocardial infarction was diagnosed if there was a classical history of chest pain documented by hospital records along with ST or Q wave changes on ECG suggestive of recent or past myocardial infarction.

Neuropathy was diagnosed if the vibratory threshold in the great toe documented by Biothesiometer (Bio Medical Instrument Co, Newbury, Ohio, USA) exceeded 25.

Peripheral vascular disease was diagnosed using Doppler recording of pressure tracings using a KODY vaslab machine (Kody Labs, Madras). An ankle brachial pressure index of less than 0.9 was considered as evidence of peripheral vascular disease.

\section{STATISTICS}

Statistical analysis were done using SPSS PC + 4.0.1. version. Student's $t$ test was used to compare the means of continuous variables
Table 2 Prevalence of microalbuminuria in relation to duration of diabetes

\begin{tabular}{|c|c|c|c|}
\hline $\begin{array}{l}\text { Duration of } \\
\text { diabetes } \\
\text { (years) }\end{array}$ & & $\begin{array}{l}\text { Odds } \\
\left(95^{\circ}\right.\end{array}$ & $p$ Value \\
\hline $\begin{array}{l}\leqslant 5 \\
5-10 \\
1-15 \\
6-20 \\
20\end{array}$ & $\begin{array}{l}237 / 776(30.4) \\
133 / 349(38.1) \\
85 / 171(49.7) \\
42 / 84(50.0) \\
21 / 45(46.7)\end{array}$ & $\begin{array}{l}- \\
1.4(1.06 \text { to } 1.8) \\
2.3(1.6 \text { to } 3.9) \\
2.3(1.4 \text { to } 3.7) \\
2.0(1.04 \text { to } 3.8)\end{array}$ & $\begin{array}{l}-\overline{0.02} \\
<0.00001 \\
0.0005 \\
0.04\end{array}$ \\
\hline \multicolumn{4}{|c|}{$\begin{array}{l}\text { CI = confidence interval. } \\
\text { and } \chi^{2} \text { test was used to compare proportions. } \\
\text { Multiple logistic regression analysis was done } \\
\text { using microalbuminuria as the dependent vari- } \\
\text { able and age, body mass index, duration of } \\
\text { diabetes, fasting plasma glucose, HbAlc, } \\
\text { serum cholesterol, serum triglycerides, serum } \\
\text { creatinine, systolic and diastolic blood pressure } \\
\text { as independent variables. }\end{array}$} \\
\hline
\end{tabular}

\section{Results}

The 1425 patients studied included 876 males and 549 females. Overall 518 had microalbuminuria $(36.3 \%, 95 \%$ confidence interval (CI) 33.8 to 38.9$)$. Prevalence of microalbuminuria among males was $32.1 \%(95 \% \mathrm{CI}$ 31.0 to 37.4$)$ and among females, $39.9 \%(95 \%$ CI 35.7 to 44.1 ).

Table 1 presents the clinical and biochemical characteristics of the normoalbuminuric and microalbuminuric patients. The microalbuminuric patients were older and had a longer duration of diabetes compared with the normoalbuminuric group $(p<0.001)$. The microalbuminuric patients had significantly increased systolic and diastolic blood pressure compared to normoalbuminuric subjects $(\mathrm{p}<0.01)$. Fasting plasma glucose and $\mathrm{HbAlc}$ concentrations were significantly higher in the microalbuminuric group compared with the normoalbuminuric subjects $(\mathrm{p}<0.001)$. Serum creatinine $(p<0.001)$ values were found to be significantly higher in the microalbuminuric group. Serum triglycerides and cholesterol values were not significantly different in both groups. Prevalence of all complications were higher among the patients with microalbuminuria compared to the normoalbuminuric subjects $(p<0.001)$.

Table 2 presents the prevalence of microalbuminuria in relation to duration of diabetes. Altogether $27.5 \%$ of the newly diagnosed diabetic subjects had microalbuminuria. The prevalence of microalbuminuria increased with increase in duration of diabetes. Taking duration $\leqslant 5$ years as the reference, the odds ratios for duration of diabetes 6-10,11-15,16-20, and $>20$ years respectively were calculated. The odds ratio for microalbuminuria showed a statistically significant increase with increase in duration of diabetes.

Figure 1 shows the cumulative prevalence of microalbuminuria in relation to duration of diabetes. It can be seen that the prevalence increased with increase in duration of diabetes until 10 years and thereafter remained unchanged.

Table 3 shows the results of the multiple logistic regression analyses using microalbuminuria as the dependent variable. Age, 


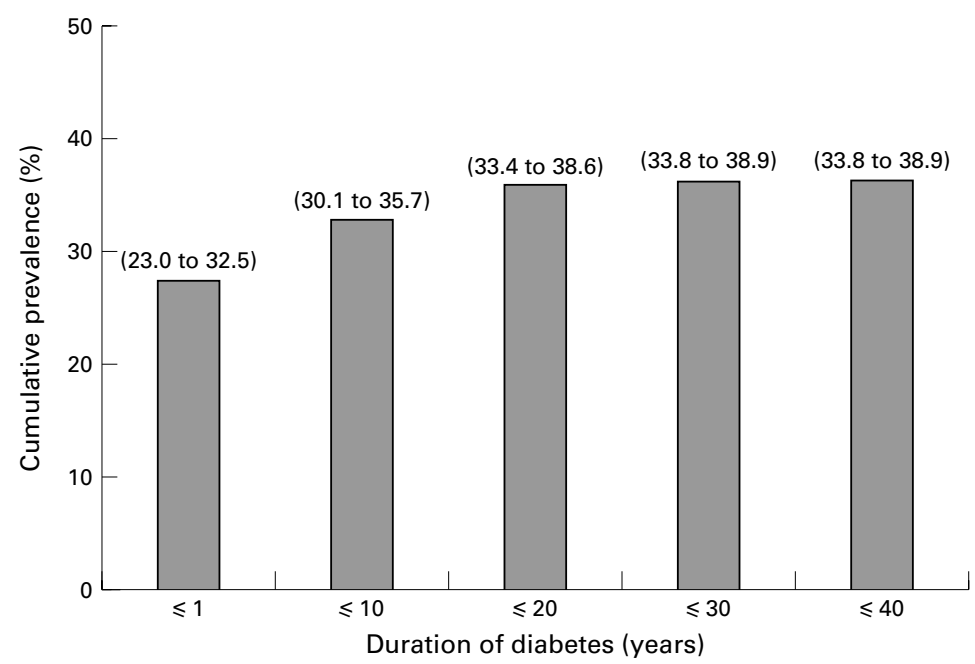

Figure 1 Cumulative prevalence of microalbuminuria in relation to duration of diabetes; figures in parentheses are $95 \%$ confidence intervals.

Table 3 Multiple logistic regression analysis using microalbuminuria as a dependent variable

\begin{tabular}{lllll}
\hline Varible & $\beta$ & SE $\beta$ & $p$ Value & Odds ratio (95\% CI) \\
\hline Age (years) & 0.25 & 0.06 & $<0.0001$ & $1.3(1.1$ to 1.4$)$ \\
Diastolic BP (mm Hg) & 0.43 & 0.08 & $<0.0001$ & $1.5(1.3$ to 1.8$)$ \\
HbA1c (\%) & 0.29 & 0.068 & $<0.0001$ & $1.3(1.2$ to 1.5$)$ \\
Fasting plasma glucose (mg/dl) & 0.23 & 0.074 & 0.002 & $1.3(1.1$ to 1.5$)$ \\
Duration of diabetes (years) & 0.18 & 0.052 & 0.005 & $1.2(1.1$ to 1.3$)$ \\
\hline
\end{tabular}

$\mathrm{CI}=$ confidence interval.

Microalbuminuria was taken as the dependent variable. The following categories were taken as independent variables; sex was a discrete variable, other variables like age, body mass index, systolic blood pressure (BP), diastolic BP, fasting plasma glucose, glycated haemoglobin (HbA1c), duration of diabetes, serum cholesterol, serum triglycerides and creatinine were continuous variables.

diastolic blood pressure, HbA1c, fasting plasma glucose, and duretion of diabetes showed a significant association with microalbuminuria.

\section{Discussion}

Various epidemiological and cross sectional studies have reported marked variation in the prevalence of microalbuminuria. ${ }^{17-21}$ Earlier studies on Asian immigrant Indians and native Indians have suggested a high prevalence of microalbuminuria. ${ }^{19-21}$ Gupta et al reported a prevalence of $26.6 \%$ in 65 type 2 north Indian non-proteinuric patients, ${ }^{19}$ while John et al reported a prevalence of $19.7 \%$ from a tertiary hospital in Vellore, south India, ${ }^{22}$ and Vijay et al reported that $15.7 \%$ had proteinuria among 600 type 2 diabetic patients studied at a diabetic centre in Chennai city. ${ }^{23}$ Studies in the white UK population revealed a prevalence of microalbuminuria of $7 \%-9 \%,{ }^{24}{ }^{25}$ while in Mexican Americans, it was $31 \%,{ }^{26}$ Pima Indians $26 \%,{ }^{27}$ Nauruans $42 \%,{ }^{18}$ and Hispanic Americans $35 \%{ }^{28}$

This variation in prevalence can be attributed to factors such as differences in populations, in the definitions of microalbuminuria, method of urine collection, etc. However this could also reflect true differences in the ethnic susceptibility to nephropathy. Earlier studies by Vijay et al from Madras (Chennai) ${ }^{29}$ have demonstrated a familial clustering of diabetic nephropathy among south Indian type 2 diabetic subjects. Genetic susceptibility linked to angiotensin encoding gene as shown in OjiKree Indians could also be an important determinant for development of diabetes renal disease. $^{30}$

In the present study the prevalence of microalbuminuria across the genders were not statistically different. Earlier studies have reported an increased prevalence of microalbuminuria in men compared with women. ${ }^{31}$ Because women have a lower creatinine excretion than men there is, however, a problem about using the albumin creatinine ratio when comparing prevalence across genders. Thus some authors use a lower threshold for men than women. ${ }^{32}$

The causal risk factors for microalbuminuria are raised blood pressure and poor glycaemic control. Some studies have revealed duration of diabetes, male sex, and pre-existing retinopathy as major risk factors for microalbuminuria. ${ }^{20}$ In our study, multiple logistic regression analysis revealed age, duration of diabetes, diastolic blood pressure, $\mathrm{HbA} 1 \mathrm{c}$, and fasting plasma glucose as the risk factors for microalbuminuria. Gupta et al reported HbA1c to be associated with microalbuminuria, ${ }^{19}$ John et al reported male sex, older age, longer duration of diabetes, poor glycaemic control, and raised blood pressure as risk factors of microalbuminuria, ${ }^{22}$ while Vijay et al reported duration of diabetes, systolic and diastolic blood pressure, age of the patient, and serum creatinine to be associated with proteinuria. ${ }^{23}$ Age was reported as one of the risk factors in the Wisconsin study, ${ }^{20}$ in a Danish population study, ${ }^{33}$ and in the Pima Indians. ${ }^{27}$ The association of glycaemic control with microalbuminuria has been well established by various studies. ${ }^{20} 262733$ Other factors which are reported to be associated with microalbuminuria are alcohol intake, ${ }^{20}$ foot ulcers, ${ }^{34}$ and smoking. ${ }^{35}$

Microalbuminuria has also been reported to be associated with generalised vascular disease. $^{36}$ In our study we observed that the microalbuminuric patients had a significantly higher prevalence of ischaemic heart disease compared with normoalbuminuric patients. Retinopathy was also common among the microalbuminuric group. Similar associations have been reported in the Danish population ${ }^{33}$ and in the UK. ${ }^{25}$

One of the limitations of this study is that it is a clinic based study. This could have introduced some degree of referral bias. However the prevalence of microalbuminuria is similar to that reported in other studies. ${ }^{37}$

In conclusion, the prevalence of microalbuminuria in this clinic based south Indian type 2 diabetic study is $36.7 \%$ and the risk factors are similar to that reported among Europeans. Given the high prevalence of diabetes in Indians with over 20 million diabetics already and the numbers expected to increase to 57 million diabetics by the year 2025 , this could place considerable burden on the health budgets of this country. This calls for early detection and good control of diabetes to reduce the burden of diabetic kidney disease in the future. 
1 Cordonnier D, Bayle F, Benhamou PY, et al. Future trends f management of renal failure in diabetics. Kidney Int 1993;43:8-13.

2 US Renal Data System. 1989 Annual data report. Bethesda, MD: National Institute of Diabetes and Digestive and Kidney Diseases, 1989.

3 Mogensen CE, Steffes MW, Deckert T, et al. Functional and morphological renal manifestations in diabetes mellitus. Diabetologia 1981;21:89-93.

4 Viberti GC, Keen $\mathrm{H}$. The patterns of proteinuria in diabetes mellitus: relevance of pathogenesis and prevention of diabetic nephropathy. Diabetes 1984;33:686-92.

5 Alzaid A. Microalbuminuria in patients with NIDDM: an overview. Diabetes Care 1996;19:79-89.

6 Parving HH, Gall MA, Skott P, et al. Prevalence and causes of albuminuria in non-insulin dependent diabetic patients. Kidney Int 1990;41:758-62.

7 Yudkin JS, Forrest RD, Johnson CA. Microalbuminuria as predictor of vascular disease in non-diabetic subjects. Lancet 1988;ii:530-3.

8 Haffner SM, Stern MP, Gruber KK, et al. Microalbuminuria: potential marker for increased cardio-
vascular risk factors in non-diabetic subjects? Arteriosclerosis vascular risk factor

9 Damsgaard EM, Froland A, Jorhgensen OD, et al. Microalbuminuria as a predictor of increased mortality in lderly people. BMF 1990;300:297-00.

10 Groop L, Ekstrand A, Forsblom C, et al. Insulin resistance, hypertension and microalbuminuria in patients with type 2 (non-insulin-dependent) diabetes mellitus. Diabetologia 1993;36:642-7.

11 Niskanen L, Laakso M. Insulin resistance is related to albuminuria in patients with type II (non-insulin-dependent) diabetes mellitus. Metabolism 1993:42:1541-5.

12 King H, Auberti RE, Herman WH. Global burden of diabetes, 1995-2025. Prevalence, numerical estimated and projections. Diabetes Care 1998;2:1414-31.

13 Ramachandran A, Snehalatha C, Latha E, et al. Rising prevalence of NIDDM in an urban population in India. prevalence of NIDDM in an
Diabetologia 1997;40:232-7.

14 World Health Organization. Diabetes mellitus. Report of a WHO study group. Geneva: World Health Organization, Technical Report Series, No 727, 1985.

15 Mohan V, Meera R, Premalatha G, et al. Frequency of proeinuria in type 2 diabetes mellitus seen at a diabetes centre in southern India. Postgrad Med $\mathcal{F} 2000 ; 76: 569-73$.

16 Joint National Committee on Detection, Evaluation and reatment of high blood pressure. The fifth report of the Joint National Committee on Detection, evaluation and treatment of high blood pressure (JNC-V). Arch Intern Med 1993;153:154-83.

17 Neil A, Hawkins M, Potok M, et al. A Prospective population-based study of microalbuminuria as a predictor of mortality in NIDDM. Diabetes Care 1993;7:996-03.

18 Collins VR, Dowse GK, Finch CF, et al. Prevalence and risk factors for micro and macroalbuminuria in diabetic subjects and entire population of Nauru. Diabetes 1989;38:1602-10.

19 Gupta DK, Verma LK, Khosla PK, et al. The prevalence of microalbuminuria in diabetes: a study from north India. microalbuminuria in diabetes: a study

20 Klein R, Klein BEK, Moss SE Prevalence of microalbumin uria in older-onset-diabetes. Diabetes Care 1993;16:1325-9.
21 Allawi J, Rao PV, Gilbert R, et al. Microalbuminuria in noninsulin-dependent diabetes: its prevalence in Indian compared with Europid patients. BMF 1988;296:462-4.

22 John L, Rao PS, Kanagasabapathy AS. Prevalence of diabetic nephropathy in non insulin dependent diabetes. Indian F Med Res 1991;94:24-9.

23 Vijay V, Snehalatha C, Ramachandran A, et al. Prevalence of proteinuria in non-insulin dependent diabetes. F Assoc Physicians India 1994;42:792-4.

24 Gatling W, Knight C, Mullee MA, et al. Microalbuminuria in diabetes: a population study of the prevalence and an assessment of three screening tests. Diabet Med 1988;5:343-

25 Marshall SM, Alberti KGMM. Comparison of the prevalence and associated features of abnormal albumin excretion in insulin-dependent and non-insulin-dependent diabetes. O 7 Med 1989;70:61-71.

26 Haffner SM, Morales PA, Gruber MK, et al. Cardiovascular risk factors in non-insulin dependent diabetic subjects with microalbuminuria. Arterioscler Thromb 1993;13:205-10.

27 Nelson RG, Kunzelman CL, Pettit DJ, et al. Albuminuria in type 2 (non-insulin-dependent) diabetes mellitus and impaired glucose tolerance in Pima Indians. Diabetologia 1989;32:870-6.

28 Hamman RF, Franklin GA, Mayer EJ, et al. Microvascular complication of NIDDM in Hispanics and non-Hispanic whites. Diabetes Care 1991;14:655-63.

29 Vijay V, Snehalatha C, Shina K, et al. Familial aggregation of diabetic kidney disease in type 2 diabetes in south India. Diabetes Res Clin Pract 1993;43:167-71.

30 Hegele RA. Uncovering rare mutations: an unforeseen complication of routine genotyping of APOE. Clin Chem 1999;45:1579-81.

31 Mather HM, Chaturvedi N, Kehely AM. Comparison of prevalence and risk factors for microalbuminuria in south Asians and Europeans with type 2 diabetes mellitus. Diabet Med 1998;15:672-7.

32 Krolewski AS, Laffel LM, Krolewski M, et al. Glycosylated haemoglobin and the risk of microalbuminuria in patients with insulin dependent diabetes mellitus. $N$ Engl $f$ Med 1995;332:1251-5.

33 Schmitz A, Vaeth M. Microalbuminuria: a major risk factor in non-insulin-dependent diabetes: a 1-year follow-up study of 503 patients. Diabet Med 1987;5:126-34.

34 Gall MA, Rossing P, Skott P, et al. Prevalence of micro-and macroalbuminuria, arterial hypertension, retinopathy and large vessel disease in European type 2 (non-insulinlarge vessel disease in European type 2 (non-insulin-

35 Olivarius N, Andreasen AH, Keiding N, et al. Epidemiological study of renal involvement in newly-diagnosed middle aged and elderly diabetic patients: cross-sectional data from the population based study "Diabetes Care in General Practice", Denmark. Diabetologia 1993;36:1007-16.

36 Deckert T, Feldt-Rasmussen B, Borch-Johnsen $\mathrm{K}$, et al. Albuminuria reflects widespread vascular damage. The Steno hypothesis. Diabetologia 1989;32:219-26.

37 Viswanathan $M$, Snehalatha C, Bhattacharyya PK, et al. Microalbuminuria in NIDDM patients in south India. Indian f Med Res 1991;94:125-9. 